\title{
The use of surface drifting floats in the monitoring of oil spills. The Prestige case
}

\author{
Emilio GARCÍA-LADONA ${ }^{1}$, Jordi SALAT ${ }^{1}$, Evilio del RÍO${ }^{1}$, Agustí JULIÀ ${ }^{1}$, Oscar CHIC ${ }^{1}$, \\ Jordi FONT ${ }^{1}$, Alejandro ORFILA ${ }^{2}$, Alberto ALVAREZ ${ }^{2}$, Gotzon \\ BASTERRETXEA ${ }^{2}$, Gonzalo VIZOSO ${ }^{2}$, Oreste PIRO $^{2}$, Joaquin TINTORÉ2, Sonia \\ CASTANEDO ${ }^{3}$, Miguel GIL COTO ${ }^{4}$, José Luis HERRERA ${ }^{4}$ and Clara LLEBOT $^{1}$ \\ ${ }^{1}$ Institut de Ciències del Mar (CMIMA-CSIC), Passeig Marítim 37-49, E-08003 Barcelona (Spain). \\ ${ }^{2}$ Institut Mediterrani d'Estudis Avançats, IMEDEA, (CSIC-UIB), Palma de Mallorca (SPAIN). \\ ${ }^{3}$ Grupo de Ingeniería Oceanográfica y de Costas, Univ. de Cantabria, Santander (Spain). \\ ${ }^{4}$ Instituto de Investigacions Mariñas (IIM-CSIC), Vigo (Spain)
}

\begin{abstract}
The location and the way the accident of the old tanker Prestige occurred implied a great challenge for the organization and coordination of actions to fight against the oil pollution. Although the use of Lagrangian floats was made in other incidents in the past the characteristics of the Prestige accident indicated the need to deploy a relative great number of buoys as a major novelty respect to similar accidents. The purpose of this contribution is to describe the operational actions performed during this particular accident, and to show the use of Lagrangian floats as an efficient procedure to improve the management and advice for such catastrophic events.
\end{abstract}

\section{INTRODUCTION}

Among the decisions made during the management of the Prestige catastrophe, it was proposed to release Lagrangian floats in parallel with the French authorities on the basis of their experience with the Erika incident (Girin, 20002). The purpose was to track the biggest oil spots position and trajectory and to provide some feedback and/or validation for the marine currents and dispersion forecast. Here, we describe the aspects relative to such a system with special relevance to the use of Lagrangian buoys as a novel and successful procedure to improve forecasting of similar events.

\section{RESULTS AND DISCUSSION}

A total of 10 drifters were available for deployment in the area and were tracked through the ARGOS system. For an overview of the information given by the buoys, in figure 1 we have represented the ensemble of trajectories followed by all the buoys during the whole tracking period.

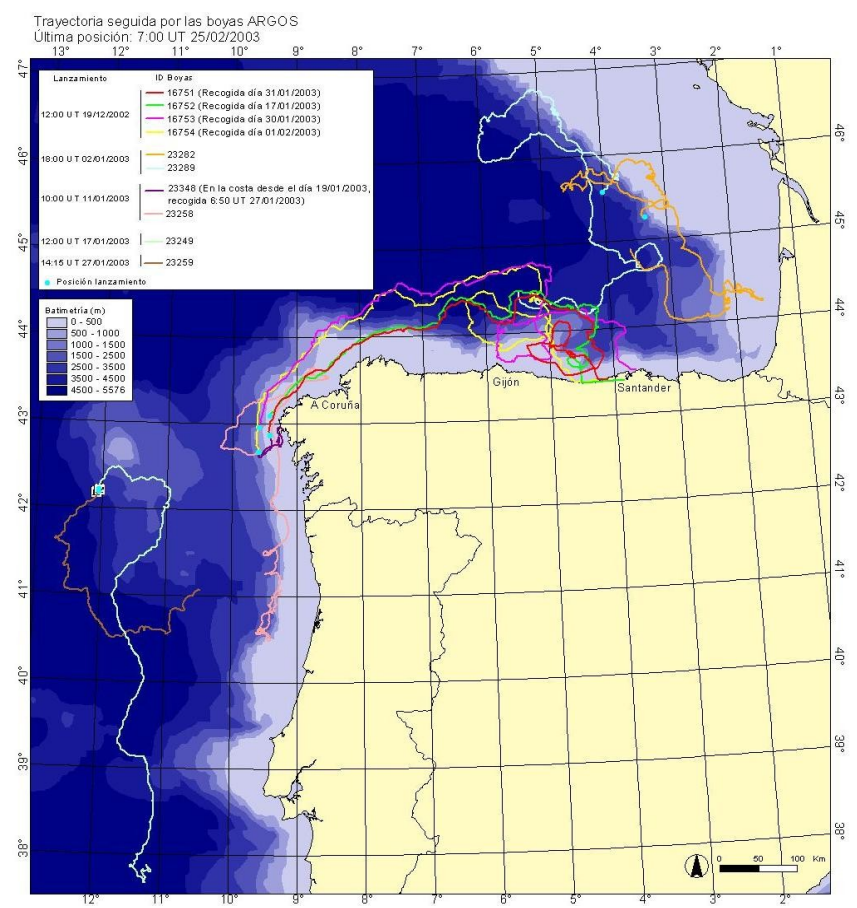

Figure 1: Overall view of the ensemble of drifters during the monitoring period. 
Despite the rather evident response to wind action when wind is intense, the buoys trajectories roughly reveal the marine current regime in the region. In the Iberian shelf region the buoys released on the shelf progressed according to the main trend of the PCC current following the coastal and shelf shape (Haynes \& Barton, 1991, Pérez et al., 2001, Martins et al., 2002). Some examples show the qualitative close correlation of buoys and clouds of oils spills (fig. 2).

a)

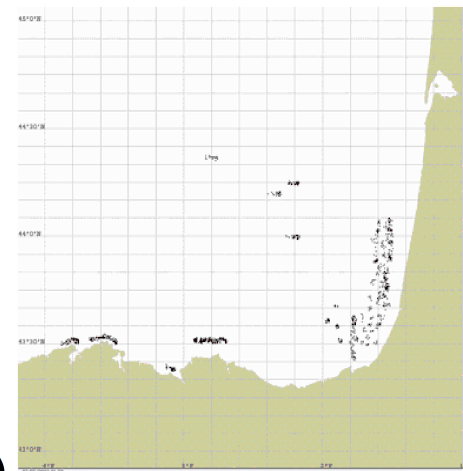

b)

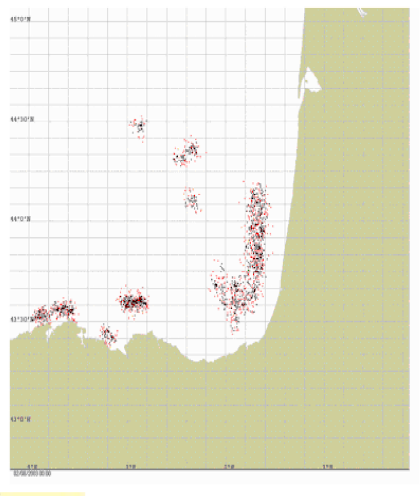

c)

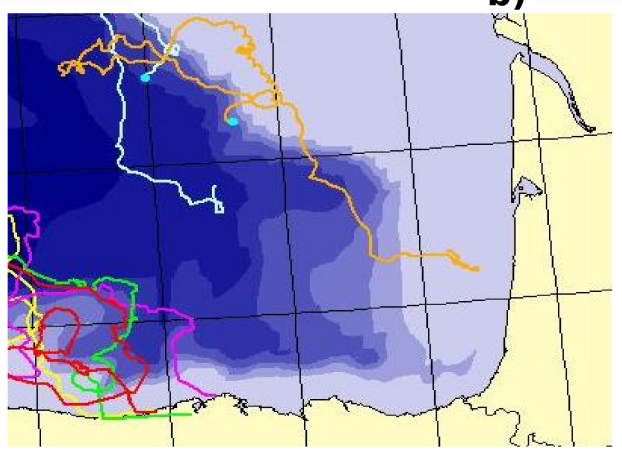

Figure 2: Left) Initial situation of several oil spills detected from visual inspection and used as initial conditions of the oil spills models. Center) Forecast evolution of the spills 3 days later. Right) Buoys trajectories in the region for the same period. The simulation corresponds to the period between the 4 and 6 February 2003.

The number of drifters was obviously not enough but their evolution was in roughly general agreement with the forecast trajectory of oil spills though more detailed and careful re-analysis must be done to confirm it. Besides of the characteristic circumstances of the Prestige accident which favoured an unusual spreading of the oil pollution over a large area, our results are encouraging and the major conclusion, extracted from our limited experience in the management of such events, is to remark the importance of using surface drifters as a tool to better manage future situations similar to those found within the Prestige. The buoy data was particularly useful for calibration of oil spill dispersion models. It served to estimate the optimal values for wind drag and wave coefficients in the Lagrangian model. In such case, the agreement between simulated and real data was in general rather reasonable and accurate.

Acknowledgements. This a contribution to ESEOO (VEM2003-20577) funded by the McyT.

\section{REFERENCES}

Girin M. (2002). Du Nakhodka à l'Erika. Actes de colloque du Cedre, Brest, France, 162 pages (available at http://www.le-cedre.fr/fr/publication/act coll/c nakhod.html).

Haynes R. and E.D. Barton (1991). Lagrangian observations in the iberian coastal transition zone. J. Geophys. Res., 96, C8, pp:14731-14741.

Pérez F.F., Castro C.G., Álvarez-Salgado X.A. and A.F. Ríos (2001). Coupling between the Iberian basin -- scale circulation and the Portugal boundary current system: a chemical study. Deep-Sea Res. I. 48, 1519-1533.

Martins C.S., Hamann M. and A.F.G. Fiúza (2002). Surface circulation in the eastern North Atlantic, from drifters and altimetry. J. Geophys. Res., 107, C12, 3217, doi:10.1029/2000JC000345. 